http://heanoti.com/index.php/hn

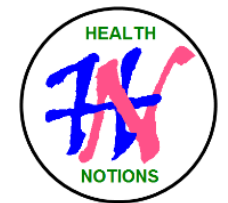

RESEARCH ARTICLE

URL of this article: http://heanoti.com/index.php/hn/article/view/hn30107

\title{
Preparation and Characteristics of NLC Coenzym Q10 with A Combination of Hyaluronic Acid
}

\author{
Nurhidayah Sarifuddin ${ }^{1}$,Widji Soerarti ${ }^{2(\mathrm{CA})}$, Noorma Rosita ${ }^{3}$ \\ ${ }^{1}$ Department of Pharmaceutical, Faculty of Pharmacy, Airlangga University, Indonesia; \\ nurhidayahsyarifuddin@ rocketmail.com \\ ${ }^{2(\mathrm{CA})}$ Department of Pharmaceutical, Faculty of Pharmacy, Airlangga University, Indonesia; \\ widjisoeratri@yahoo.com (Corresponding Author) \\ ${ }^{1}$ Department of Pharmaceutical, Faculty of Pharmacy, Airlangga University, Indonesia
}

\begin{abstract}
Coenzyme Q10, often also known as ubiquinone, coenzyme Q10 or Q10, is soluble in lipids and is naturally present in plants, animals and in mitochondria. Coenzyme Q10 functions as an antioxidant that can protect the body from damage caused by free radicals. Hyaluronic acid is known as a hydrophilic polymer derived from polysaccharides which has the ability to increase percutaneous penetration by changing the composition of tightly arranged stratum corneum cells to increase the permeability of the skin. Nanostructured Lipid Carrier is a modification of the SLN system, consisting of a mixture of solid and liquid lipids (oil), stabilized by aqueous surfactant solution, is one method to increase drug penetration through the stratum corneum because it has several advantages. The purpose of this study was to see the effect of adding hyaluronic acid to the characteristics of the Nanostructure Lipid Carrier (NLC) as anti aging. Examination of characteristics including organoletis, $\mathrm{pH}$, particle size and polidispersity index was carried out. The results of organoleptic NLC coenzym Q10-HA examination obtained dark orange color, liquid consistency, lipid efficacy odor and soft texture. The $\mathrm{pH}$ measurement results of the preparation ranged from 5.05-5.23. The results of the particle size examination ranged from $267-128 \mathrm{~nm}$ and the particle size distribution ranged between $0.308-0.200$
\end{abstract}

Keywords: Coenzym Q10, Hyaluronic Acid , NLC

\section{INTRODUCTION}

\section{Background}

Coenzym Q10 is a natural compound found in the inner membrane of the mitochondria, with the role of forming ATP as an electron carrier in the respiratory cycle in the mitochondria ${ }^{(1)}$. Networks that require large energy and high metabolic rates such as the liver, kidneys, heart and muscles have large intrinsic concentrations of Q10 compared to other tissues. The ubiquinol reduction form is a potent antioxidant compound and is able to recycle and regenerate other antioxidants such as Isopropyl palmitate and Vitamin $\mathrm{C}^{(1)}$.

There are two main routes of drug penetrating the stratum corneum, including the transepidermal pathway and the transapendagel pathway ${ }^{(2)}$. One of the factors that can affect penetration ability through intercellular and transcellular pathways is the price of the partition coefficient $(\log \mathrm{P})$. The optimal $\log \mathrm{P}$ value for the penetration of substances penetrating the stratum corneum is $2-3^{(3)}$. Coenzym Q10 is a fat soluble compound with a $\log \mathrm{P}$ of 19.4 so that coenzym Q10 has a penetration that is not good at penetrating the skin.

To increase percutaneous penetration requires a penetration enhancer (skin enhancer) that is safe and can be degraded by the body. One of the penetration enhancers that has these criteria is hyaluronic acid. Hyaluronic acid (HA) is known as a polysaccharide-derived hydrophilic polymer that has the ability to increase percutaneous penetration by changing the arrangement of the tightly arranged stratum corneum cells to increase the permeability of the $\operatorname{skin}^{(4)}$. 
The Nanostructured Lipid Carrier (NLC) is the second generation of the Solid Lipid Nanoparticle (SLN) system. Nanostructured Lipid Carrier is a modification of the SLN system, consisting of a mixture of solid and liquid (oil) lipids, stabilized by aqueous surfactant solution, is one method to increase drug penetration through the stratum corneum because it has several advantages ${ }^{(5)}$. One of the advantages is that the presence of dense lipids in the system can control drug release so that it can act as a drug reservoir. NLC formulas contain lipids and surfactants, which can increase penetration ${ }^{(6),(7)}$. Good NLC characteristics can be shown from pH value, viscosity, particle size, particle morphology, drug entrapment efficiency, drug release, in percutaneous penetration in vitro and physicochemical stability. Characteristic testing is done to determine the characteristics of a good NLC so that it can proceed to penetration testing.

\section{METHODS}

\section{Chemicals}

The materials that used in this study such as coenzym Q10 (Kangcare Bioindustry, China), hyaluronic acid, cethyl palmitate, olive oil, span 80, Tween 80, ethanol pa, sodium acetate pa, and glacial acetic acid pa (Materials that used in this study if not stated, otherwise it has Pharmaceutical grade purity).

\section{Place and time of research}

This research was conducted in October 2018 until December 2018. It was held at the Department of Pharmaceutical, Faculty of Pharmacy, Airlangga University, Indonesia.

\section{Preparation of NLC coenzym Q10 with hyaluronic acid (HA)}

The NLC coenzym Q10-HA system was made using the High Shear Homogenization method. In the first stage, the oil phase in the form of cetyl palmitate, olive oil and the active ingredient coenzym Q10 were melted at $60^{\circ} \mathrm{C}$. At the same time, Tween 80 , span 80 , HA, ethanol and acetate buffer $\mathrm{pH} 5.0 \pm 0.2$ were heated to a temperature of $60^{\circ} \mathrm{C}$ in separate containers. Then Tween 80 and Span 80 were added to the mixture of oil phase and coenzym Q10, stirred with High Shear Homogenizer at a speed of $5000 \mathrm{rpm}$ for 5 minutes. After that, the water phase was added gradually, such as the ethanol mixture and buffer acetate, into the oil phase with the same temperature, time and speed. After the last droplet, the ultraturrax speed was increased to a speed of $16,000 \mathrm{rpm}$ for 5 minutes. The cooling step which was carried out by transferring the NLC and the High Shear Homogenizer onto the hot plate, then stirred using a magnetic stirrer at a speed of $500 \mathrm{rpm}$ to reach room temperature.

\section{Fourier transform infrared (FTIR)}

Analysis of coenzym Q10 FTIR NLC spectrum with HA combination. Before analysis, 2 mg samples were mixed with $300 \mathrm{mg} \mathrm{KBr}$ powder for pellets. Pellet KBr was observed at 4000-450 / cm using Jasco FT-IR 5300, Easton MD, USA.

\section{Organoleptic}

Organoleptic examination was done visually including shape, color, and smell.

\section{pH test}

$\mathrm{pH}$ measurements were carried out using a calibrated $\mathrm{pH}$ meter. Electrode was inserted into $50 \mathrm{~mL}$ of the formula and then the number was indicated by the $\mathrm{pH}$ meter.

\section{Droplet size and Polidispersity index (PI)}

The size and distribution of particle size were carried out using the DelsaTM Nano Sub Micron Particle Size Analyzer. Formula was weighed about 1.0 gram plus aquadest until volume of $10 \mathrm{~mL}$. The sample was inserted into the cuvette then the cuvette was inserted into the sample holder. The device was turned on and the particle size menu was selected. The data, which was observed, was the average droplet diameter and polydispersity index (PI). Polydispersity index (PI) was described variations in the sample. PI values less than 0.2 indicate that the sample was monodispersion. 


\section{Statistical analysis}

Statistical analysis was performed by one-way analysis of variance (ANOVA) for repeated measurements. The post hoc (Bonferroni) test was used to perform multiple comparison analysis (SPSS program, USA, version 15 ) and differences were considered significant at a level of $\mathrm{p}<0.05$.

\section{RESULTS}

\section{Organoleptis}

Table 1. The results of organoleptic examination of the NLC coenzym Q10-HA system

\begin{tabular}{ccccc}
\hline \multirow{2}{*}{ Formula } & \multicolumn{4}{c}{ Organoleptic examination } \\
\cline { 2 - 5 } & Color & Smell & Consistency & Texture \\
\hline F1 & Orange & The distinctive smell of lipids & Liquid & Soft \\
F2 & Orange & The distinctive smell of lipids & Liquid & Soft \\
F3 & Orange & The distinctive smell of lipids & Liquid & Soft \\
\hline
\end{tabular}

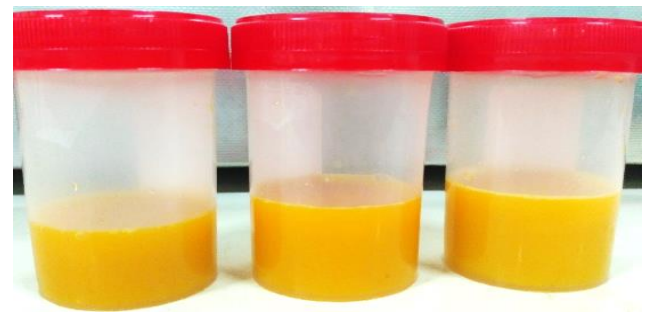

A $\quad$ B

B C

Figure 1. NLC Coenzym Q10-HA formula with various concentrations of A) Formula 1 coenzym Q10 with $1 \%$ HA; B) Formula 2 coenzym Q10 with $1.5 \%$ HA; C) Formula 3 coenzym Q10 with $2 \%$ HA.

pH Test

Table 2. The results of the $\mathrm{pH}$ testing of the NLC coenzym Q10-HA system

\begin{tabular}{ccccccccc}
\hline Formula & \multicolumn{9}{c}{ Ingredients } & \multicolumn{2}{c}{ Mean \pm SD } \\
\cline { 2 - 8 } & $\begin{array}{c}\text { Coenzyme } \\
\text { Q10 }\end{array}$ & HA & $\begin{array}{c}\text { Cethyl } \\
\text { palmitate }\end{array}$ & $\begin{array}{c}\text { Olive } \\
\text { oil }\end{array}$ & $\begin{array}{c}\text { Span } \\
80\end{array}$ & $\begin{array}{c}\text { Tween } \\
\text { Ethanol }\end{array}$ & $\mathrm{pH}$ \\
F1 & 1 & 1 & 4.8 & 1.8 & 1.8 & 18.44 & 3.42 & $5.21 \pm 0.017$ \\
F2 & 1 & 1.5 & 4.8 & 1.8 & 1.8 & 18.44 & 3.42 & $5.13 \pm 0.017$ \\
F3 & 1 & 2 & 4.8 & 1.8 & 1.8 & 18.44 & 3.42 & $5.07 \pm 0.2$ \\
\hline
\end{tabular}

\section{Particle Size dan polidispersity index}

Table 3. The results of particle size measurement and coenzym Q10 NLC particle size distribution with HA combination

\begin{tabular}{ccc}
\hline Formula & \multicolumn{2}{c}{ Mean \pm SD } \\
\cline { 2 - 3 } & Particle Size & PI \\
\hline F1 & $128.1 \pm 1.22$ & $0.308 \pm 0.01$ \\
F2 & $155.3 \pm 11,95$ & $0.28 \pm 0.04$ \\
F3 & $267.3 \pm 147.44$ & $0.200 \pm 0.08$ \\
\hline
\end{tabular}




\section{Fourier Transform Infrared (FT-IR)}

FTIR coenzym Q10 spectra, HA and FTIR spectra NLC coenzym Q10 system with HA combination was shown in the figure.

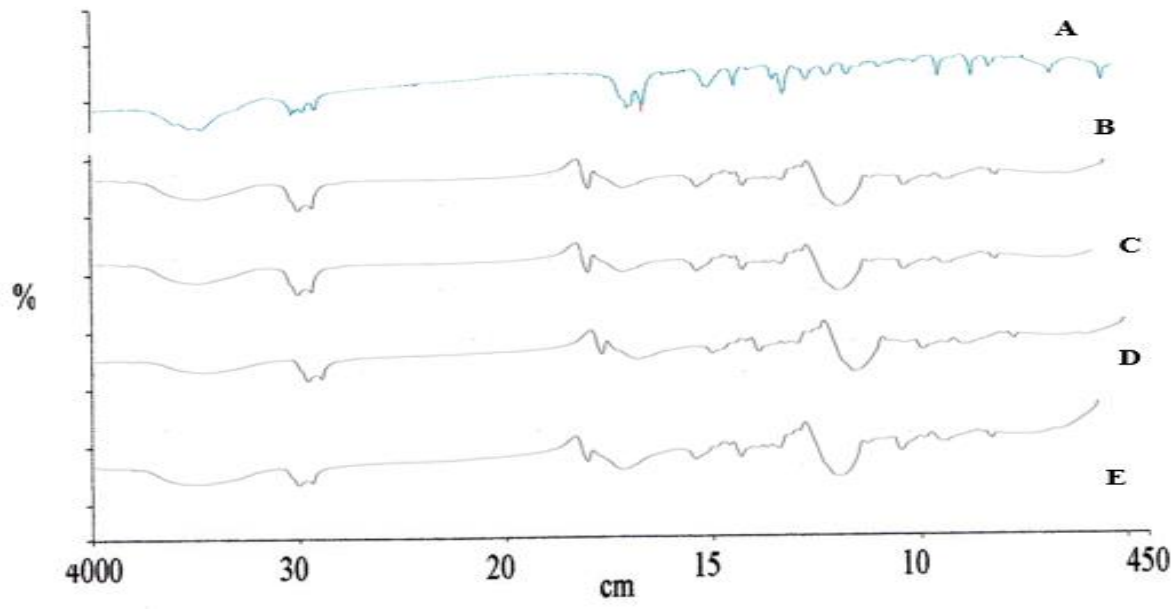

Figure 2. (A) Coenzym Q10 infrared spectrum (B) spectrum infrared blank (C) infrared spectrum formula 1 (D) infrared spectrum formula 2 and (E) infrared spectrum formula 3.

\section{DISCUSSION}

NLC characteristics of coenzym Q10 with HA combination are determined. Based on the examination of organoleptic NLC with HA combination, a system with a liquid consistency was produced, dark orange and has a soft texture (table 1 and figure 1). The greater the concentration of HA in the NLC system, the system consistency increases. The $\mathrm{pH}$ produced in each formula ranged from 5.05-5.23 (table 2 and figure 2 ) where the $\mathrm{pH}$ is in the $\mathrm{pH}$ range of the skin which is 4.0-6.5, so that it can minimize the occurrence of irritation, because the $\mathrm{pH}$ too acidic can cause pain in the skin and $\mathrm{pH}$ that is too alkaline can cause irritation because the $\mathrm{pH}$ is too alkaline can cause fungal and bacterial infections ${ }^{(8)}$.

Examination of particle size and particle size distribution was carried out using the Delsa Nano Particle Size Analyzer tool. The results of examination of particle size revealed that there were no significant differences in each formula. While for the measurement results of particle size distribution it can be seen that F1 with a small particle size of 128.1 has a large particle size distribution. The smaller the particle size the particle size distribution is increasingly heterogeneous, whereas if the particle size is greater, the particle size distribution value will be more homogeneous ${ }^{(9)}$.

Based on FTIR results it is known that the IR spectrum in all NLC formulas coenzym Q10-HA is identical to NLC (blank). This shows that there is no chemical bond between the NLC (blank) system and coenzym Q10 which can result in loss of Q10 coenzym activity in the NLC system.

\section{CONCLUSION}

The coeznym Q10 formulation with HA combination affects the characteristics. Increased HA levels lowered $\mathrm{pH}$, but the $\mathrm{pH}$ of the preparation was still in the range of skin $\mathrm{pH}$, elevated HA levels increased particle size, but the particle size of the dosage was still in the range of particle size of NLC which was 100-1000 nm.

\section{REFERENCES}

1. Jung HA, et al . Antioxidant Xanthones from the Pericarp of Garcinia mangostana (Mangosteen), Agric Food Chem. 2009;54:2077-2082.

2. Tosato, Zamboni V, Ferrini A, Cesari M. The Aging Process and Potential Interventions to Extend Life Expectancy. Clin. Interv. Aging. 2007;2(3):401-412.

3. Benson HAE. Skin Structure, Function and Permeation. In: Benson HAE, Watkinson AC. (Eds). Transdermal and Topical Drug Delivery. New Jersey: Wiley; 2012.

4. Navarro-Sarabia F, Coronel P. A 40-Month Multicentre "Randomised Placebo Controlled Study to Assess The Efficacy and Carryover Effect of Repeated Intra-Articular Injections of Hyaluronic Acid in Knee Osteoartritis": The AMELIA Project. Ann Rheum Dis. 2012. 
5. Mendes M, Nunus SCC, Sousa JJ, Pais AACC, Vitorino C. Expanding Transdermal Delivery with Lipid Nanoparticles: A New Drug-in-NLC-in-Adhesive Design. American Chemical Society. 2017;14(6):20992115.

6. Khurana S, Jain NK, Bedi PMS. Development and Characterization of a Novel Controlled Release Drug Delivery System Based on Nanostructured Lipid Carriers Gel for Meloxicam. Life Sciences. 2013;93:763772.

7. Patel D, Dasguptas S, Dey S, Ramani YR, Ray S, Mazumder B. Nanostructured Lipid Carriers (NLC)-Based Gel for the Topical Delivery of Aceclofenac: Preparation, Characterization, and in Vivo Evaluation. Sci Pharm. 2013;80:749-764.

8. Zlotogorski A. Gilead L, Jonas F, Horev L, Klaus SN. Dermatology and Venereology. Journal of the Europan Academy of Dermatology and Venereology. 1998;11(1):S1-S26,1-98.

9. Souto EB, Müller RH. Lipid Nanoparticles (Solid Lipid Nanoparticle and Nanosturctured Lipid Carriers) for Cosmetic, Dermal, and Transdermal Aplication. In Thassu D, Deleers M, Pathak Y. Nanoparticulate Drug Delivery System. New York: Informa Healthcare USA, Inc.; 2007. 